\title{
Visceral and spinal cord protection during thoracoabdominal aortic aneurysm repair: Clinical and laboratory update
}

\author{
Gabriele Di Luozzo, MD
}

The best method to protect the visceral and spinal cord during extensive aortic replacement remains debatable. Numerous surgeons have appropriately argued for their preferences because of the excellent clinical outcomes at their respective institutions. However, a scientific explanation for the greater success of a specific technique compared with the others has rarely been apparent. Many investigators have attempted to explain why certain adjuncts to minimize the risk of spinal cord injury (SCI) during thoracoabdominal aortic aneurysm (TAA) repair have physiologic benefits. Laboratory studies have shed light on some aspects of spinal cord protection, including the dynamics of blood flow and the anatomy of the blood supply to the spinal cord. However, despite the lack of clear scientific evidence for some of the protection techniques, surgeons have continued to achieve improved clinical outcomes.

\section{VISCERAL PROTECTION WITH DEEP HYPOTHERMIA}

Deep hypothermic circulatory arrest (DHCA) has been successful in providing acceptable neurologic and endorgan protection when applied to the treatment of the proximal aorta and arch aneurysms. ${ }^{1,2}$ In many cases of aortic arch repairs, DHCA $\left(15^{\circ} \mathrm{C}-18^{\circ} \mathrm{C}\right)$ has afforded protection of visceral function for intervals as long as 90 minutes of lower body arrest. ${ }^{3,4}$ Aneurysms of the distal aorta, which are not amenable to the placement of an aortic crossclamp, have also been managed with HCA. Kouchoukos ${ }^{5}$ have had great success with a single-stage approach to aortic arch and descending aortic aneurysms using HCA. On the basis of these clinical scenarios, HCA has been applied to the repair of complex TAA.

Proponents of HCA have used this technique to reduce tissue metabolism and oxygen consumption in preparation for a period of ischemia. ${ }^{2}$ Applying HCA to TAA obviates

\footnotetext{
From the Department of Cardiothoracic Surgery, Mount Sinai School of Medicine, New York, NY

Disclosures: Dr Di Luozzo has nothing to disclose with regard to commercial support. Presented at The American Association for Thoracic Surgery Aortic Surgery Symposium 2012, April 26-27, 2012, New York, NY.

Received for publication April 25, 2012; revisions received Oct 12, 2012; accepted for publication Nov 28, 2012; available ahead of print Dec 26, 2012.

Address for reprints: Gabriele Di Luozzo, MD, Department of Cardiothoracic Surgery, Mount Sinai School of Medicine, 1190 Fifth Ave, Box 1028, New York, NY 10029 (E-mail: gabriele.diluozzo@mountsinai.org).

J Thorac Cardiovasc Surg 2013;145:S135-8

0022-5223/\$36.00

Copyright (c) 2013 by The American Association for Thoracic Surgery

http://dx.doi.org/10.1016/j.jtcvs.2012.11.053
}

the need for proximal and sequential aortic clamping and minimizes aortic manipulation and embolization. Selective perfusion of the visceral arteries is not usually performed, because it is not required with HCA. In contrast, it is a necessary adjunct when mild hypothermia is used. In our daily practice, HCA is conducted by cannulating the femoral arteries unless significant aortic atheroma or thrombus is present. In such cases, we use the axillary artery. The patient is cooled to a bladder temperature of $15^{\circ} \mathrm{C}$, with a minimum cooling period of 30 minutes. If all visceral arteries need reimplantation, we commonly suture the limbs of a trifurcated graft to a rim of aortic tissue surrounding the individual ostia. The main limb of the trifurcated graft is sutured to the main aortic graft as soon as possible to begin perfusion of the viscera. In cases of type I TAA, the distal anastomosis to the visceral segment of the abdominal aorta is beveled, eliminating the need for individual grafts.

One of first publications on the use of DHCA in the treatment of TAA was by Crawford and colleagues ${ }^{6}$ in 1987 , followed by reports from others of excellent early clinical outcomes using this technique. Fehrenbacher and colleagues $^{7}$ and Kulik and colleagues ${ }^{8}$ are major proponents of this approach to TAA, with published operative mortality ranging from $5 \%$ to $7.3 \%$. In a small series of descending thoracic aorta and TAA, Okita and colleagues ${ }^{9}$ reported no in-hospital deaths in cases managed with DHCA. More specifically, Fehrenbacher and colleauges ${ }^{7}$ reported an incidence of renal complications of $5.0 \%$ and of visceral complications of $3.5 \%$. Patients with chronic renal insufficiency (creatinine $>3 \mathrm{mg} / \mathrm{dL}$ ) had a net change in creatinine from baseline of less than 3\% when DHCA was used. ${ }^{10}$ In type II to IV TAA cases, the range of dialysis-dependent renal failure was $1.8 \%$ to $3.1 \%$. Other investigators reported that the need for postoperative dialysis has ranged as high as $6.9 \%$ to $11 \% .^{8,11}$

We recently reviewed our experience with the early outcomes of 262 TAA repairs during a 7-year period comparing the results using mild hypothermia and DHCA. ${ }^{12} \mathrm{~A}$ propensity score-matched analysis was performed on the data from 90 patients. We focused our analysis on reversible problems (ie, temporary dialysis, renal failure, liver dysfunction) and permanent adverse outcomes (ie, longlasting dialysis, stroke, paraplegia, and death). As the distal ischemia time-which includes the DHCA time and the time needed to re-establish lower body perfusion-increases, a significantly lower rate of reversible adverse outcomes (RAOs) occurs with DHCA than with mild hypothermia. The baseline probability of developing an 

Abbreviations and Acronyms
$\mathrm{CNP}=$ collateral network perfusion pressure
DHCA $=$ deep hypothermic circulatory arrest
HCA = hypothermic circulatory arrest
RAOs $=$ reversible adverse outcomes
SA $=$ segmental artery
SCI $=$ spinal cord injury
$\mathrm{TAA}=$ thoracoabdominal aortic aneurysm

extensive SA sacrifice. ${ }^{15}$ Blood flow to the paraspinous muscles is sevenfold greater than to the spinal cord. A surprising result, but one that correlated with the findings of subsequent vascular casting studies. ${ }^{16,17}$ In addition, the spinal cord blood flow to T8-L2, seems from these studies, to be the area most vulnerable to ischemia. It is also the area with the greatest difference in histologic damage when pigs that are paraplegic after extensive SA sacrifice were compared with pigs that recovered hind limb function.

The clinical implications of these studies is that concern with measures that ensure a stable milieu for optimal spinal cord recovery after surgery is paramount, including extreme vigilance in the immediate postoperative period with regard to blood pressure, avoidance of steal, and slow rewarming. Subsequent studies have successfully determined the collateral network perfusion pressure (CNP) by measuring the stump pressure of either L1 in pigs or the SA located in the middle of the aortic resection in surgical patients. ${ }^{18,19}$ We learned that the CNP decreases from about $70 \%$ to about $25 \%$ of the mean arterial pressure when all SAs are sacrificed and decreases further during the subsequent 5 hours. The CNP does not begin to recover until 24 hours postoperatively and does not return to baseline until 72 to 120 hours postoperatively. In surgical patients, the CNP decreases during cardiopulmonary bypass and begins to increase after pulsatile perfusion has been re-established. From the limited experience with CNP monitoring, it seems reasonable to maintain low central venous and cerebrospinal fluid pressures and to provide an elevated mean arterial pressure to maximize the CNP.

\section{MANIPULATION OF THE COLLATERAL NETWORK}

Our clinical observation of patients who had undergone extensive aortic replacement in 2 stages revealed a remarkably low incidence of SCI. ${ }^{20}$ In our animal model, we designed a 2-stage approach to extensive SA sacrifice using an open and endovascular strategy. ${ }^{21}$ The decline in CNP observed after either the first or second stage of a 2-stage protocol was significantly less than after a 1-stage approach. None of the pigs in the 2-stage group manifested clinically detectable SCI, although histologically, a degree of tissue damage was seen. These studies suggest that collateral network remodeling and/or angiogenesis occur between the 2 stages, reducing the vulnerability of the spinal cord to ischemia.

\section{ANATOMY OF THE COLLATERAL NETWORK}

Our laboratory studies and clinical experience with extensive sacrifice of the SAs have given us clues concerning the potential expansiveness of the collateral network. Perfusion of the porcine model with a low viscosity acrylic resin revealed an extensively interconnected paraspinous muscle and intraspinal vascular network ${ }^{16,17}$ (Figure 2). to spinal cord ischemia exists for several hours after 


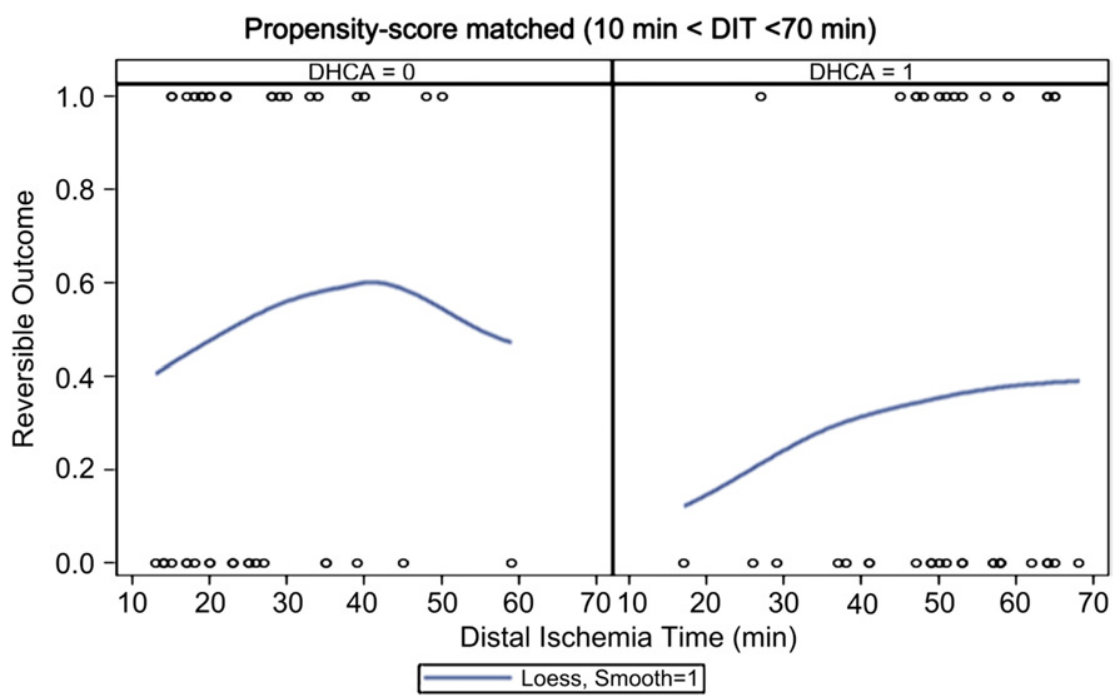

FIGURE 1. Probability of reversible adverse outcome with increasing distal ischemia time (DIT) in propensity score-matched subset plotted for non-deep hypothermic circulatory arrest (DHCA) compared with DHCA.

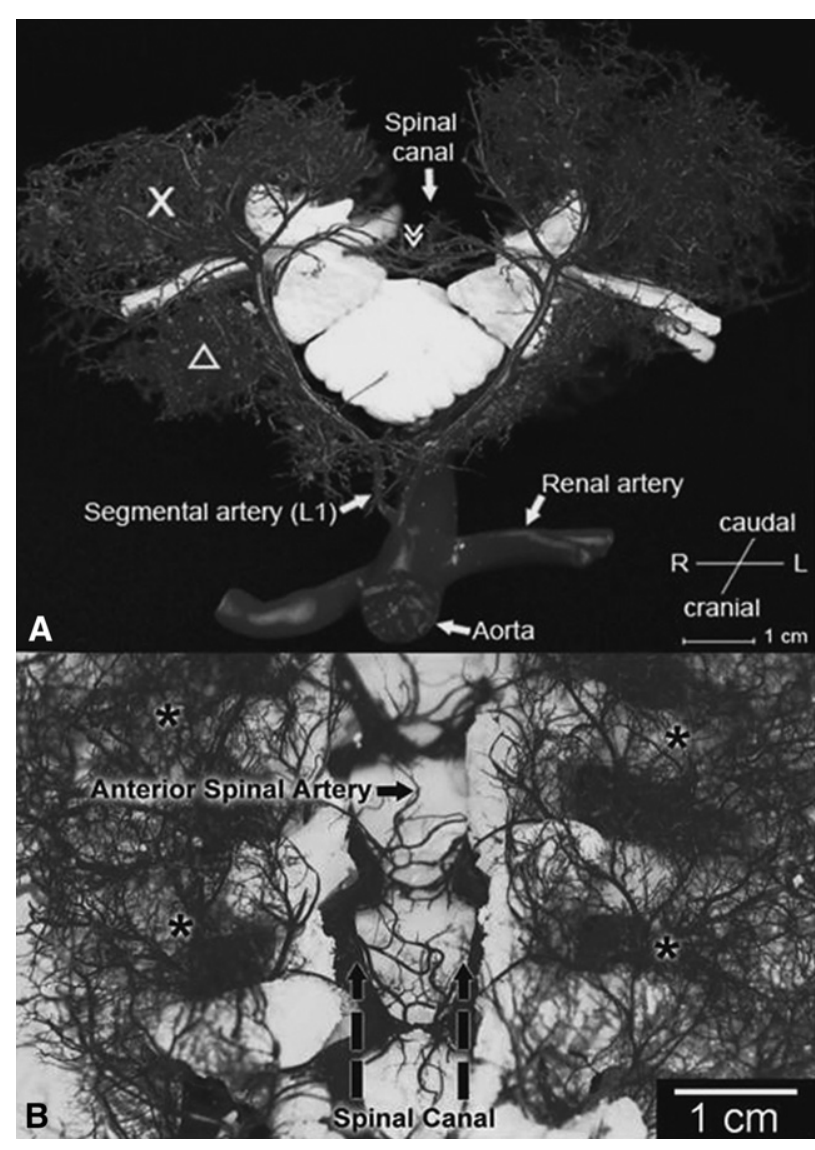

FIGURE 2. Anatomy of collateral network: A, sagittal and B, dorsal view. Macroscopic appearance of casts of pair of dorsal segmental vessels at L1. Dorsal process is removed. $X$ designates paraspinous muscular vasculature providing extensive longitudinal arterioarteriolar connections; triangle indicates iliopsoas muscle.
Collateralization between the paraspinous muscle and intraspinous vascular networks dwarfs the role of the individual SAs and supports the premise that extensive SA sacrifice is possible owing to the resiliency of the network. In clinical practice, we have routinely maintained a high mean arterial pressure postoperatively to augment blood flow through this vascular network.

\section{CONCLUSIONS}

We remain enthusiastic about the beneficial effects of hypothermia on visceral and neuronal protection. Clinical data from multiple institutions support the use of DCHA for renovisceral protection during complex aortic reconstruction. The results from our retrospective study suggest that DHCA reduces the likelihood of RAOs when a prolonged duration of distal ischemia is expected. Identifying patients who will benefit from HCA or from an elephant trunk procedure to decrease the interval of distal ischemia during the stage 2 procedure will continue to reduce the morbidity and mortality associated with open TAA repair.

SCI remains a dreaded complication after open or endovascular repair of TAAs. We are encouraged by our initial experimental studies, which have focused our attention on methods of manipulating the collateral network to eliminate the risk of paraplegia. The 2-stage approach, when feasible clinically, is promising. At present, however, this approach is limited by the morbidity associated with 2 open procedures and the limitations of current stent technology.

\section{References}

1. Griepp RB, Stinson EB, Hollingsworth JF, Buehler D. Prosthetic replacement of the aortic arch. J Thorac Cardiovasc Surg. 1975;70:1051-63. 
2. McCullough JN, Zhang N, Reich DL, Juvonen TS, Klein JJ, Spielvogel D, et al. Cerebral metabolic suppression during hypothermic circulatory arrest in humans. Ann Thorac Surg. 1999;67:1895-9; discussion 1919, 1821.

3. Spielvogel D, Etz CD, Silovitz D, Lansman SL, Griepp RB. Aortic arch replacement with a trifurcated graft. Ann Thorac Surg. 2007;83:S791-5; discussion S824, 731.

4. Spielvogel D, Halstead JC, Meier M, Kadir I, Lansman SL, Shahani R, et al. Aortic arch replacement using a trifurcated graft: simple, versatile, and safe. Ann Thorac Surg. 2005;80:90-5; discussion 95.

5. Kouchoukos NT. One-stage repair of extensive thoracic aortic disease. J Thorac Cardiovasc Surg. 2010;140(6 suppl):S150-3; discussion S185-90.

6. Crawford ES, Coselli JS, Safi HJ. Partial cardiopulmonary bypass, hypothermic circulatory arrest, and posterolateral exposure for thoracic aortic aneurysm operation. J Thorac Cardiovasc Surg. 1987;94:824-7.

7. Fehrenbacher JW, Siderys H, Terry C, Kuhn J, Corvera JS. Early and late results of descending thoracic and thoracoabdominal aortic aneurysm open repair with deep hypothermia and circulatory arrest. J Thorac Cardiovasc Surg. 2010; 140(6 suppl):S154-60; discussion S185-90

8. Kulik A, Castner CF, Kouchoukos NT. Outcomes after thoracoabdominal aortic aneurysm repair with hypothermic circulatory arrest. J Thorac Cardiovasc Surg. 2011;141:953-60.

9. Okita Y, Takamoto S, Ando M, Morota T, Yamaki F, Matsukawa R, et al. Repair for aneurysms of the entire descending thoracic aorta or thoracoabdominal aorta using a deep hypothermia. Eur J Cardiothorac Surg. 1997;12:120-6.

10. Fehrenbacher JW, Hart DW, Huddleston E, Siderys H, Rice C. Optimal endorgan protection for thoracic and thoracoabdominal aortic aneurysm repair using deep hypothermic circulatory arrest. Ann Thorac Surg. 2007;83:1041-6.

11. Sundt TM, Flemming MD, Oderich GS, Torres NE, Li Z, Lenoch J, et al. Spinal cord protection during open repair of thoracic and thoracoabdominal aortic aneurysms using profound hypothermia and circulatory arrest. J Am Coll Surg. 2011; 212:678-83; discussion 684-5.
12. Weiss AJ, Lin HM, Bischoff MS, Scheumann J, Lazala R, Griepp RB, et al. A propensity score-matched comparison of deep versus mild hypothermia during thoracoabdominal aortic surgery. J Thorac Cardiovasc Surg. 2012;143:186-93.

13. Strauch JT, Spielvogel D, Lauten A, Zhang N, Shiang H, Weisz D, et al. Importance of extrasegmental vessels for spinal cord blood supply in a chronic porcine model. Eur J Cardiothorac Surg. 2003;24:817-24.

14. Strauch JT, Spielvogel D, Lauten A, Zhang N, Shiang H, Weisz D, et al. Importance of extrasegmental vessels for spinal cord blood supply in a chronic porcine model. Rev Port Cir Cardiotorac Vasc. 2003;10:185-91.

15. Etz CD, Homann TM, Luehr M, Kari FA, Weisz DJ, Kleinman G, et al. Spinal cord blood flow and ischemic injury after experimental sacrifice of thoracic and abdominal segmental arteries. Eur J Cardiothorac Surg. 2008;33:1030-8.

16. Etz CD, Kari FA, Mueller CS, Silovitz D, Brenner RM, Lin HM, et al. The collateral network concept: a reassessment of the anatomy of spinal cord perfusion. J Thorac Cardiovasc Surg. 2011;141:1020-8.

17. Etz CD, Kari FA, Mueller CS, Brenner RM, Lin HM, Griepp RB. The collateral network concept: remodeling of the arterial collateral network after experimental segmental artery sacrifice. J Thorac Cardiovasc Surg. 2011;141:1029-36.

18. Etz CD, Homann TM, Plestis KA, Zhang N, Luehr M, Weisz DJ, et al. Spinal cord perfusion after extensive segmental artery sacrifice: can paraplegia be prevented? Eur J Cardiothorac Surg. 2007;31:643-8.

19. Etz CD, Di Luozzo G, Zoli S, Lazala R, Plestis KA, Bodian CA, et al. Direct spinal cord perfusion pressure monitoring in extensive distal aortic aneurysm repair. Ann Thorac Surg. 2009;87:1764-73; discussion 1773-4.

20. Etz CD, Zoli S, Mueller CS, Bodian CA, Di Luozzo G, Lazala R, et al. Staged repair significantly reduces paraplegia rate after extensive thoracoabdominal aortic aneurysm repair. J Thorac Cardiovasc Surg. 2010;139:1464-72.

21. Zoli S, Etz CD, Roder F, Brenner RM, Bodian CA, Kleinman G, et al. Experimental two-stage simulated repair of extensive thoracoabdominal aneurysms reduces paraplegia risk. Ann Thorac Surg. 2010;90:722-9. 